Advance Journal of Food Science and Technology 5(10): 1367-1374, 2013

DOI:10.19026/ajfst.5.3112

ISSN: 2042-4868; e-ISSN: 2042-4876

(C) 2013 Maxwell Scientific Publication Corp.

Submitted: June 25, $2013 \quad$ Accepted: July 08, 2013

Published: October 05, 2013

\title{
Research Article \\ Odor-Active (E)-4-Methyl-3-hexenoic Acid in Roasted Coffee Generated in the Maillard Reactions of L-Isoleucine with Sugars
}

\author{
Hironari Miyazato, Michiaki Nakamura, Seiji Hashimoto and Shuichi Hayashi \\ Research and Development Center, Nagaoka Perfumery Co., Ltd., 1-3-30 Itsukaichi, \\ Ibaraki, Osaka 567-0005, Japan
}

\begin{abstract}
This study describes a novel odor-active unsaturated aliphatic acid in roasted Brazilian Arabica coffee. (E)-4-Methyl-3-hexenoic acid $((E)-4 \mathrm{M} 3 \mathrm{H})$, which is responsible for a sweaty odor, was identified for the first time using Gas Chromatography-Mass Spectrometry/Olfactometry (GC-MS/O), Aroma Extract Dilution Analysis (AEDA) and Multidimensional Gas Chromatography-Mass Spectrometry (MDGC-MS); its (Z)-isomer was also determined. Additionally, we conducted a model formation experiment to detect the presence of $4 \mathrm{M} 3 \mathrm{H}$ in coffee and found that it may be produced nonstereoselectively in the Maillard reactions of L-isoleucine with sugars (xylose, fructose, glucose, rhamnose and sucrose). We also found that 2-methylbutanal derived from L-isoleucine and sugar degradation compounds such as $\alpha$-dicarbonyl compounds (glyoxal, 2-oxopropanal, 2, 3-butanedione and 2, 3pentanedione) and $\alpha$-hydroxy ketones (1-hydroxy-2-propanone and 3-hydroxy-2-butanone) are key factors in the formation of $4 \mathrm{M} 3 \mathrm{H}$. Based on these results, we propose a series of potential nonstereoselective formation pathways for $4 \mathrm{M} 3 \mathrm{H}$.
\end{abstract}

Keywords: AEDA, Arabica coffee, formation pathway, MDGC-MS, odorant

\section{INTRODUCTION}

The aroma of roasted coffee consists of more than 850 volatile odorous compounds (Flament, 2001). Odor-active compounds in coffee have not yet been determined completely, since most of these compounds are present in traces and cannot be detected in chromatographic peaks via standard Gas Chromatography (GC) techniques; however, Gas Chromatography-Olfactometry (GC-O) provides a solution to this problem. Dilution odor techniques such as Aroma Extract Dilution Analysis (AEDA) (Ullrich and Grosch, 1987) have been used to screen trace amounts of odor-active components that have a low odor threshold (Holscher et al., 1990; Blank et al., 1992). In a recent study (Miyazato et al., 2013b), we elucidated using AEDA that cis-2, 6-dimethyl-1, 4cyclohexanedione is the odor-active cyclic 1, 4diketone in roasted coffee volatile oil. A sweatsmelling, odor-active, unknown compound was also observed.

The aroma of roasted coffee is generally produced during the roasting process, which includes a variety of thermal chemical reactions such as the Maillard reaction, the Strecker reaction and caramelization (Holscher and Steinhart, 1994). In the Maillard reaction, amino acids react with sugars to produce volatile odorous compounds (Shibamoto, 1989; Mottram, 1994). The Strecker reaction occurs along with the Maillard reaction and mainly affords Strecker aldehydes derived from the corresponding amino acids (Weenen and van der Ven, 2001). A sugar decomposition reaction occurs in the Maillard reaction as well as in caramelization and provides small molecular products, e.g., $\alpha$-dicarbonyl compounds (glyoxal, 2-oxopropanal, 2, 3-butanedione and 2, 3pentanedione) and $\alpha$-hydroxy ketones (1-hydroxy-2propanone and 3-hydroxy-2-butanone) (Hollnagel and Kroh, 1998; Davídek et al., 2007; Novotný et al., 2007), which subsequently react with amino acids (Pripis-Nicolau et al., 2000) or with each other (Nishimura and Mihara, 1990) to produce several odorants. Therefore, these reactions are considered important in the generation of odorants in the roasted coffee. We assume that the sweat-smelling target odorant too may have been generated during the roasting process.

The aim of this study is twofold: to identify the sweat-smelling, unknown compound in roasted Brazilian Arabica coffee and to discuss its formation during the roasting process, by focusing primarily on the Maillard reactions of L-isoleucine with sugars.

Corresponding Author: Hironari Miyazato, Research and Development Center, Nagaoka Perfumery Co., Ltd., 1-3-30 Itsukaichi, Ibaraki, Osaka 567-0005, Japan, Tel.: +81-(0)72-623-5252; Fax: +81-(0)72-623-5251

This work is licensed under a Creative Commons Attribution 4.0 International License (URL: http://creativecommons.org/licenses/by/4.0/). 


\section{MATERIALS AND METHODS}

\section{Materials:}

Coffee: Brazilian Arabica coffee was used and the coffee beans were purchased from Unicafe Inc. (Tokyo, Japan). They were already roasted at luminosity (L)value 18 and ground using a mill mixer, IFM-700G (Iwatani, Osaka, Japan).

Chemicals: (Z)-and (E)-4-Methyl-3-hexenoic acids $(4 \mathrm{M} 3 \mathrm{H})$ were synthesized stereoselectively based on the literature (Miyazato et al., 2013a). Glycine, L- $\alpha-$ alanine, L-valine, L-leucine, L-isoleucine, D- $(+)-$ xylose, D-(-)-fructose, D-(+)-glucose, L-(+)-rhamnose, 2, 3-butanedione and a phosphate buffer solution ( 0.1 $\mathrm{mol} / \mathrm{L}, \mathrm{pH}$ 6.0) were purchased from Nacalai tesque (Kyoto, Japan). Sucrose, glyoxal (40\% solution) and 2methylbutanal were purchased from Wako Pure Chemical Industries (Osaka, Japan). 2-Oxopropanal (40\% solution), 2, 3-pentanedione and 1-hydroxy-2propanone $(90 \%)$ were purchased from Sigma-Aldrich Japan (Tokyo, Japan). 3-Hydroxy-2-butanone was purchased from Inoue Perfumery MFG (Tokyo, Japan).

\section{Methods:}

Isolation of the roasted coffee volatile oil: Simultaneous Steam Distillation-Extraction (SDE) was performed on the ground coffee (251 g) using a LikensNickerson extractor, with pentane/diethyl ether (50/50) for $2 \mathrm{~h}$, consistent with literature (Holscher et al., 1990), to obtain the coffee volatile oil (ab. $200 \mu \mathrm{L}$ ).

Ion-exchange chromatography using an oasis max cartridge: The coffee volatile oil $(100 \mu \mathrm{L})$ was dissolved in methanol $(200 \mu \mathrm{L})$ and distilled water $(5$ $\mathrm{mL}$ ) and the mixture was subsequently charged on an Oasis MAX cartridge (Nihon Waters, Tokyo, Japan) that was conditioned in advance with methanol $(1 \mathrm{~mL})$ followed by distilled water $(2 \mathrm{~mL})$. Elution was performed with developing solvents as follows: 50 $\mathrm{mmol} / \mathrm{L}$ sodium acetate $(\mathrm{pH} 7.0)(1 \mathrm{~mL})$, methanol (2 $\mathrm{mL}$ ) and lastly methanol/2\% formic acid solution (2 $\mathrm{mL}$ ), in accordance with methods described in the literature (Akutsu et al., 2006; Miyazato et al., 2013a). The final fraction was mixed with brine $(50 \mathrm{~mL})$. The aqueous phase was extracted with diethyl ether (50 $\mathrm{mL}$ ), dried over anhydrous sodium sulfate and subsequently concentrated on a rotary evaporator (760 $\mathrm{mm} \mathrm{Hg}, 40^{\circ} \mathrm{C}$ ) to afford the concentrated acid fraction (ab. $50 \mu \mathrm{L}$ ).

The maillard reactions of amino acids with sugars: Mixtures of each amino acid (25 mmol) (L-isoleucine, glycine, L- $\alpha$-alanine, L-valine and L-leucine) with each sugar $(25 \mathrm{mmol})$ (xylose, fructose, glucose, rhamnose and sucrose) in the phosphate buffer (50 mL, pH 6.0) were heated for $1 \mathrm{~h}$ at $120^{\circ} \mathrm{C}$ in a laboratory autoclave (Model ES-315; Tomy Seiko, Tokyo, Japan). After the addition of sodium chloride (10 g) and diethyl ether $(100 \mathrm{~mL})$, the reaction mixtures were stirred for $24 \mathrm{~h}$ at room temperature. The organic phases were dried over anhydrous sodium sulfate, filtered and subsequently concentrated on a rotary evaporator $\left(760 \mathrm{mmHg}, 40^{\circ} \mathrm{C}\right)$ to yield corresponding volatile ethereal solutions (ab. 2 $\mathrm{mL}$ ).

The maillard reactions of glycine with sugars in the presence of 2-methylbutanal: Mixtures of glycine (10 mmol), 2-methylbutanal (10 mmol) and each sugar (10 mmol) (xylose, fructose, glucose, rhamnose and sucrose) in the phosphate buffer $(50 \mathrm{~mL}, \mathrm{pH} 6.0)$ were heated for $1 \mathrm{~h}$ at $120^{\circ} \mathrm{C}$ in the autoclave.

Reactions of $L$-isoleucine with the sugar degradation compounds: Mixtures of L-isoleucine $(10 \mathrm{mmol})$ and each sugar degradation compound (glyoxal, 2oxopropanal, 2, 3-butanedione, 2, 3-pentanedione, 1hydroxy-2-propanone and 3-hydroxy-2-butanone) (10 $\mathrm{mmol})$ in the phosphate buffer $(50 \mathrm{~mL}, \mathrm{pH} 6.0)$ were heated for $1 \mathrm{~h}$ at $120^{\circ} \mathrm{C}$ in the laboratory autoclave.

Reactions of 2-methylbutanal with the sugar degradation compounds in the presence of glycine: Mixtures of glycine $(10 \mathrm{mmol}), 2$-methylbutanal (10 $\mathrm{mmol}$ ) and each sugar decomposition compound (10 mmol) (glyoxal, 2-oxopropanal, 2, 3-butanedione, 2, 3pentanedione, 1-hydroxy-2-propanone and 3-hydroxy2-butanone) in the phosphate buffer (50 mL, pH 6.0) were heated for $1 \mathrm{~h}$ at $120^{\circ} \mathrm{C}$ in the autoclave.

\section{Analysis:}

Gas Chromatography-Mass Spectrometry/ Olfactometry (GC-MS/O): GC-MS/O analysis was performed using a GC-17A gas chromatograph (Shimadzu, Kyoto, Japan) coupled to a mass spectrometer (GCMS-QP5050, Shimadzu), equipped with an olfactory port (OP275, GL Sciences Inc., Tokyo, Japan). The chromatograph was fitted with either an InertCap WAX (polyethylene glycol) fused silica capillary column $(60 \mathrm{~m} \times 0.32 \mathrm{~mm}$ i.d., film thickness $0.25 \mu \mathrm{m}$ ) (GL Sciences Inc.), or an InertCap 1 $(100 \%$ methylpolysiloxane) fused silica capillary column $(60 \mathrm{~m} \times 0.25 \mathrm{~mm}$ i.d., film thickness $0.25 \mu \mathrm{m})$ (GL Sciences Inc.), which were used as the interface with both the mass spectrometer and the olfactory port via a splitter. The inlet system was a split/splitless mode and inlet pressure was $170 \mathrm{kPa}$. The injector temperature was held at $250^{\circ} \mathrm{C}$. Purified helium $(\geq 99.99995 \%)$ was used as the carrier gas at a flow rate of $3.8 \mathrm{~mL} / \mathrm{min}\left(\right.$ at $70^{\circ} \mathrm{C}$ ). The oven temperature was programmed from $70^{\circ} \mathrm{C}$ (held for $5 \mathrm{~min}$ ) to $240^{\circ} \mathrm{C}$ at $3^{\circ} \mathrm{C} / \mathrm{min}$ and the interface temperature was $250^{\circ} \mathrm{C}$. The mass spectrometer operated at an Electron Impact (EI) value of $70 \mathrm{eV}$. Data were collected in a full scan mode and the mass scan range was $\mathrm{m} / z$ 27-300. Olfactory detection was performed during this chromatographic separation. The olfactory port was heated to $260^{\circ} \mathrm{C}$ and 
damp air (nitrogen/oxygen $=80 / 20$ ) was constantly pulled at a rate of $30 \mathrm{~mL} / \mathrm{min}$ through the head of the port during its operation. The Kováts Retention Index (RI) was calculated using retention times of unbranched hydrocarbons from C6 to C27 (Kováts, 1958).

\section{Multidimensional Gas Chromatography-Mass Spectrometry (MDGC-MS): MDGC-MS analysis was performed using an Agilent two-dimensional gas} chromatography system, constructed with Agilent $6890 \mathrm{~A}$ gas chromatographs in the first (1-D) and second dimensions (2-D). The 1-D chromatograph was equipped with a Flame Ionization Detector (FID), while the 2-D chromatograph was connected to a mass spectrometer (Agilent 5973N MSD, Agilent Technologies Japan, Tokyo, Japan). The 1-D chromatograph was coupled to the 2-D chromatograph via a Gerstel Cryo Trap System (CTS1) (Gerstel K.K., Tokyo, Japan). The 1-D chromatograph was equipped with a Gerstel Multi Column Switching System MCS2 (Gerstel K.K.) for the heart-cutting operation and was fitted with a TC-WAX (polyethylene glycol) fused silica capillary column $(30 \mathrm{~m} \times 0.25 \mathrm{~mm}$ i.d., film thickness $0.25 \mu \mathrm{m})$ (GL Sciences Inc.); the 2-D chromatograph, on the other hand, was equipped with an InertCap $1(100 \%$ methylpolysiloxane) fused silica capillary column $(60 \mathrm{~m} \times 0.25 \mathrm{~mm}$ i.d., film thickness $0.25 \mu \mathrm{m})$ (GL Sciences Inc.). Purified helium ( $\geq 99.99995 \%$ ) was used as the carrier gas at a flow rate of $1.2 \mathrm{~mL} / \mathrm{min}\left(\right.$ at $70^{\circ} \mathrm{C}$ ). The inlet pressure was 103 $\mathrm{kPa}$ and the inlet system was in a split/splitless mode. The temperatures of both the injector and transfer line were held at $250^{\circ} \mathrm{C}$. The FID temperature was $250^{\circ} \mathrm{C}$, $\mathrm{H} 2$ flow was $60 \mathrm{~mL} / \mathrm{min}$, air flow was $100 \mathrm{~mL} / \mathrm{min}$ and make up flow (He) was $20 \mathrm{~mL} / \mathrm{min}$. The mass spectrometer operated at an EI value of $70 \mathrm{eV}$, with the ion source temperature at $230^{\circ} \mathrm{C}$. Data were collected in a full scan mode and the mass scan range was $m / z 27$ 300. The heart-cutting operation was performed from 42.0 to $43.8 \mathrm{~min}$ on the 1-D chromatograph. The oven temperature was programmed as follows: 1-D-from $70^{\circ} \mathrm{C}$ (held for $5 \mathrm{~min}$ ) to $240^{\circ} \mathrm{C}$, at $3{ }^{\circ} \mathrm{C} / \mathrm{min}$, 2-D-from $70^{\circ} \mathrm{C}$ (held for $45 \mathrm{~min}$ ) to $240^{\circ} \mathrm{C}$, at $3^{\circ} \mathrm{C} / \mathrm{min}$. The temperature of the CTS1 was maintained mostly at $250^{\circ} \mathrm{C}$ during operation; however, while repeating the heart-cutting operation thrice or fourfold in order to increase concentration, its temperature was held constant at $-20^{\circ} \mathrm{C}$ by using liquid nitrogen. After the CTS1 temperature was increased to $250^{\circ} \mathrm{C}$ at $25^{\circ} \mathrm{C} / \mathrm{sec}$, the 2-D oven temperature was programmed from $70^{\circ} \mathrm{C}$ (held for $5 \mathrm{~min}$ ) to $240^{\circ} \mathrm{C}$ at $3^{\circ} \mathrm{C} / \mathrm{min}$ for analysis.

Analysis of the coffee volatile oil and acid fraction: The coffee volatile oil and acid fraction were analyzed via $\mathrm{GC}-\mathrm{MS} / \mathrm{O}$ to observe the target compound. A sample $(1.0 \mu \mathrm{L})$ was injected in a split ratio of 1:10. The acid fraction was analyzed using MDGC-MS to obtain the mass spectrum by repeating heart-cutting operation fourfold. A sample $(3.0 \mu \mathrm{L})$ was injected in a split ratio of 1:5.

Analysis of volatiles occurring in the maillard and related reactions: Extracted volatile ethereal solutions were analyzed via GC-MS/O in order to sniff the target compound. The sample $(4.0 \mu \mathrm{L})$ was injected in a split ratio of 1:5. A sample (L-isoleucine/xylose) was analyzed using MDGC-MS; the heart-cutting operation was repeated thrice. The sample $(1.0 \mu \mathrm{L})$ was injected in a split ratio of 1:5.

Identification of the target compound: The target compound was identified by comparing its RI, mass spectrum and odor quality via GC-O with a synthesized standard compound.

\section{RESULTS AND DISCUSSION}

Identification of the sweat-smelling, unknown, odoractive compound in roasted coffee: In our previous study (Miyazato et al., 2013b), the AEDA of a roasted Brazilian Arabica coffee brew showed a sweat-smelling unknown compound $\mathrm{A}$, which was perceived as being at RI $=2060$ (InertCap WAX) and 1070 (InertCap 1) and had the highest Flavor Dilution (FD) factor of 729 (Table 1). On the basis of odor description, we expected the unknown odorant to be a volatile carboxylic acid. Since a corresponding chromatographic peak did not appear when using standard GC-(EI) MS, a deeper analysis was performed.

The coffee volatile oil was extracted from the roasted Brazilian Arabica coffee grounds by SDE and was subsequently chemically treated using an Oasis MAX cartridge to afford the acid fraction which contained a high concentration of the target unknown compound $\mathrm{A}$. The fraction was analyzed via MDGC(EI) MS, showed a chromatographic peak (Fig. 1) and a mass spectrum of the target compound A was obtained (Fig. 2). The target unknown compound A was found to be $(E)$-4-methyl-3-hexenoic acid $((E)-4 \mathrm{M} 3 \mathrm{H})$, a sweatsmelling unsaturated volatile aliphatic acid, by comparing its RI, mass spectrum and odor quality via GC-O with a synthesized standard substance, as detected in yuzu (Citrus junos) (Miyazato et al., 2013a), kabosu (Citrus sphaerocarpa) (Tomiyama et al., 2012) and laundry (Takeuchi et al., 2012).

As shown in Table 1, $(E)-4 \mathrm{M} 3 \mathrm{H}$ had the higher FD factor value than the other volatile acids such as 2methylbutanoic acid, 3-methylbutanoic acid and phenylacetic acid, as well as 3-phenylpropionic acid, previously identified in roasted coffee brew (Miyazato et al., 2013b). This demonstrated that $(E)-4 \mathrm{M} 3 \mathrm{H}$ is one of the most important odor-active compounds in roasted coffee. 
Adv. J. Food Sci. Technol., 5(10): 1367-1374, 2013

Table 1: Comparison of the sweat-smelling unknown compound A with $(E)$-and $(Z)$-4-methyl-3-hexenoic acids and the other volatile acids previously identified in roasted coffee (Miyazato et al., 2013b)

\begin{tabular}{|c|c|c|c|c|}
\hline Compound & $\mathrm{RI}_{\text {polar }}{ }^{1}$ & $\mathrm{RI}_{\text {apolar }}^{2}$ & Odor description $^{3}$ & FD-factor ${ }^{4,5}$ \\
\hline Unknown A & 2060 & 1071 & Sweaty & 729 \\
\hline \multicolumn{5}{|l|}{ Standard compounds } \\
\hline (E)-4-methyl-3-hexenoic acid $((E)-4 \mathrm{M} 3 \mathrm{H})$ & 2059 & 1070 & Sweaty & \\
\hline (Z)-4-methyl-3-hexenoic acid ((Z)-4M3H) & 2047 & 1062 & Sweaty & \\
\hline \multicolumn{5}{|l|}{ Other volatile acids in roasted coffee ${ }^{6}$} \\
\hline 2-methylbutanoic acid & 1669 & 824 & Cheese-like & 243 \\
\hline 3-methylbutanoic acid & 1669 & 813 & Cheese-like & 243 \\
\hline phenylacetic acid & 2568 & 1212 & Chocolate-like & 81 \\
\hline 3-phenylpropionic acid & 2629 & 1305 & Honey-like & 729 \\
\hline
\end{tabular}

${ }^{1}$ : InertCap WAX $(60 \mathrm{~m} \times 0.32 \mathrm{~mm}$ i.d., film thickness $0.25 \mu \mathrm{m}){ }^{2}{ }^{2}$ : InertCap $1(60 \mathrm{~m} \times 0.25 \mathrm{~mm}$ i.d., film thickness $0.25 \mu \mathrm{m}){ }^{3}$; Evaluated via GC-

$\mathrm{O} ;{ }^{4}$ : AEDA performed in a previous study (Miyazato et al., 2013b); ${ }^{5}$ : Ranged from 27 to $729 ;{ }^{6}$ : Based on the literature (Miyazato et al., 2013b)

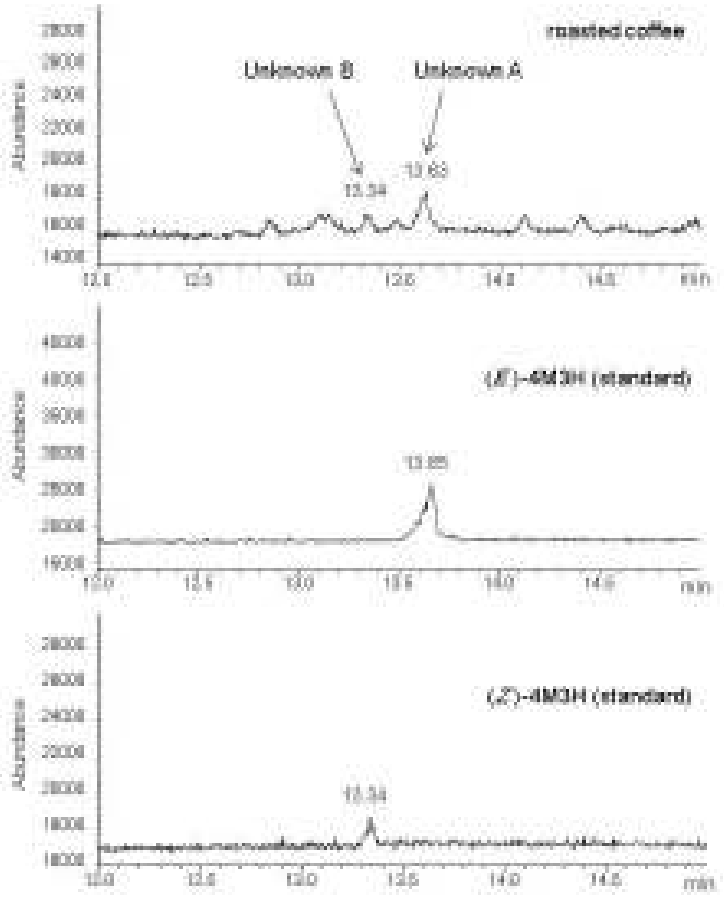

Fig. 1: The total ion chromatogram of 4-methyl-3-hexenoic acid $(4 \mathrm{M} 3 \mathrm{H})$ found in roasted coffee, via Multidimensional Gas Chromatography-Mass Spectrometry (MDGC-MS) (column (second dimension), InertCap1; (E)-4M3H, $13.65 \mathrm{~min} ;(Z)$ 4M3H, $13.34 \mathrm{~min}$ )

Interestingly, (Z)-4M3H (unknown compound B) was also detected in roasted coffee (Fig. 1 and 2) the same as that in laundry (Takeuchi et al., 2012), but not in yuzu (Miyazato et al., 2013a).

Mizutani et al. (1971) and Narushima et al. (1982) explained that only the $(E)$-isomer of $4 \mathrm{M} 3 \mathrm{H}$ forms biologically from linalool and myrcene, via enzymecatalyzed oxidative degradations. The detected (Z)isomer suggests the possibility of different formation pathways for $4 \mathrm{M} 3 \mathrm{H}$ in coffee. We do not think that the pathways are biological and stereoselective and assume that $4 \mathrm{M} 3 \mathrm{H}$ may be thermally formed during the roasting process. In order to test the validity of our hypothesis, we carried out a survey of the generation of $4 \mathrm{M} 3 \mathrm{H}$ in chemical reactions that occur during the roasting process.
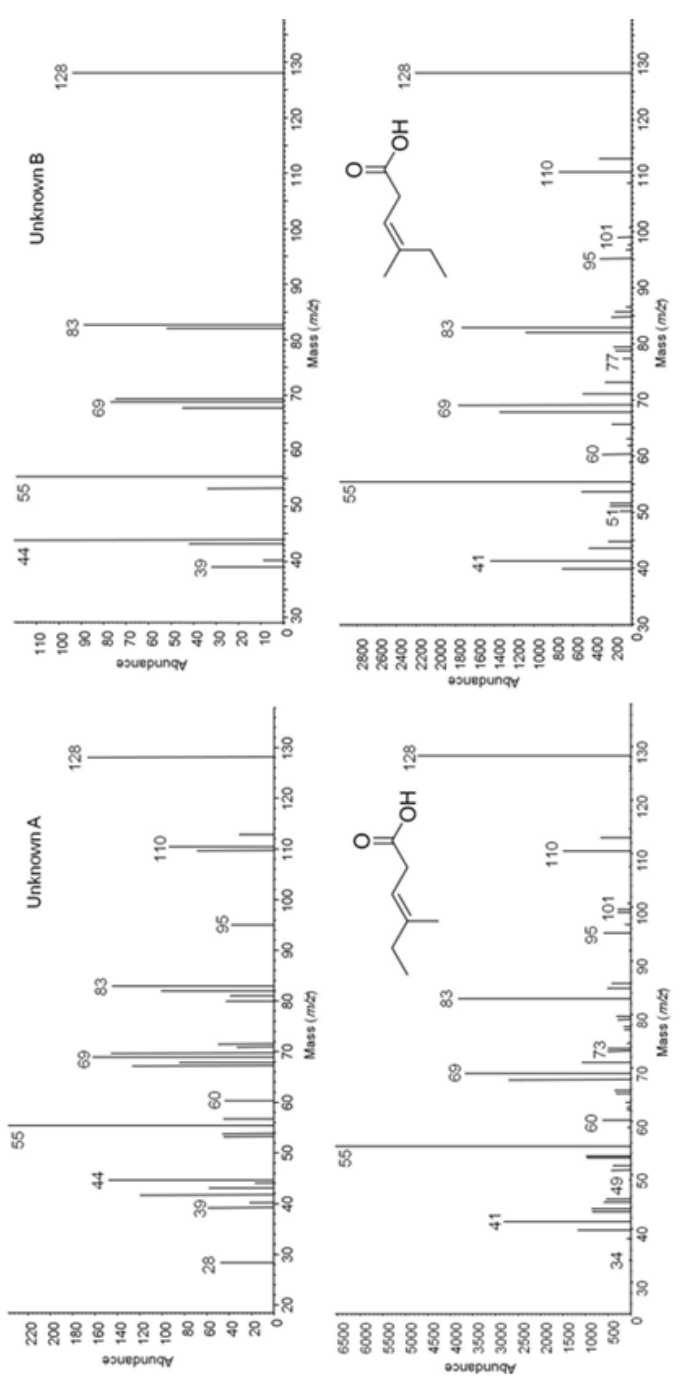

Fig. 2: Mass spectra of unknown compounds (A and B) in roasted coffee and $(E)$-and $(Z)$-4-methyl-3-hexenoic acid $(4 \mathrm{M} 3 \mathrm{H})$ as the standard substances

Generation of $4 \mathrm{M} 3 \mathrm{H}$ in the maillard and related reactions: Volatile acid concentration increases following the roasting of green coffee (Wöhrmann et al., 1997), because acyl sugar conjugates present in the coffee (Weckerle et al., 2002) may decompose and chemical reactions may occur during roasting (Holscher and Steinhart, 1994). For example, the Strecker reaction 
Adv. J. Food Sci. Technol., 5(10): 1367-1374, 2013

Table 2: Sniffing search of $(E)$-4-methyl-3-hexenoic acid $((E)-4 \mathrm{M} 3 \mathrm{H})$ formed in the maillard and related reactions

\begin{tabular}{|c|c|c|c|c|}
\hline No. & Amino acid & Sugar & Strecker aldehyde & $(E)-4 \mathrm{M} 3 \mathrm{H}$ \\
\hline $1^{1,3}$ & L-isoleucine & xylose & & + \\
\hline $2^{1}$ & glycine & xylose & & - \\
\hline $3^{1}$ & $\mathrm{~L}-\alpha$-alanine & xylose & & - \\
\hline $4^{1}$ & L-valine & xylose & & - \\
\hline $5^{1}$ & L-leucine & xylose & & - \\
\hline $6^{1}$ & L-isoleucine & fructose & & + \\
\hline $7^{1}$ & L-isoleucine & glucose & & + \\
\hline $8^{1}$ & L-isoleucine & rhamnose & & + \\
\hline $9^{1}$ & L-isoleucine & sucrose & & + \\
\hline $10^{2}$ & glycine & xylose & 2-methylbutanal & + \\
\hline $11^{2}$ & glycine & fructose & 2-methylbutanal & + \\
\hline $12^{2}$ & glycine & glucose & 2-methylbutanal & + \\
\hline $13^{2}$ & glycine & rhamnose & 2-methylbutanal & + \\
\hline $14^{2}$ & glycine & sucrose & 2-methylbutanal & + \\
\hline $15^{2}$ & L-isoleucine & glyoxal & & + \\
\hline $16^{2}$ & L-isoleucine & 2-oxopropanal & & + \\
\hline $17^{2}$ & L-isoleucine & 2,3-butanedione & & + \\
\hline $18^{2}$ & L-isoleucine & 2,3-pentanedione & & + \\
\hline $19^{2}$ & L-isoleucine & 1-hydroxy-2-propanone & & + \\
\hline $20^{2}$ & L-isoleucine & 3-hydroxy-2-butanone & & + \\
\hline $21^{2}$ & glycine & glyoxal & 2-methylbutanal & + \\
\hline $22^{2}$ & glycine & 2-oxopropanal & 2-methylbutanal & + \\
\hline $23^{2}$ & glycine & 2,3-butanedione & 2-methylbutanal & + \\
\hline $24^{2}$ & glycine & 2,3-pentanedione & 2-methylbutanal & + \\
\hline $25^{2}$ & glycine & 1-hydroxy-2-propanone & 2-methylbutanal & + \\
\hline $26^{2}$ & glycine & 3-hydroxy-2-butanone & 2-methylbutanal & + \\
\hline
\end{tabular}

${ }^{1}$ : Amino acids $(25 \mathrm{mmol})$ and sugars $(25 \mathrm{mmol})$ in phosphate buffer $(\mathrm{pH} 6.0)$ at $120^{\circ} \mathrm{C}$ for $1 \mathrm{~h}$ in an autoclave; ${ }^{2}$ : Amino acids $(10 \mathrm{mmol})$ and sugars or sugar degradation compounds $(10 \mathrm{mmol})$, with or without aldehyde $(10 \mathrm{mmol})$, in phosphate buffer $(\mathrm{pH} 6.0)$ at $120^{\circ} \mathrm{C}$ for $1 \mathrm{~h}$ in an autoclave; ${ }^{3}$ : Analyzed via MDGC-MS; ${ }^{4}$ : “+” indicates "presence”, "-” indicates "absence” in GC-O analysis

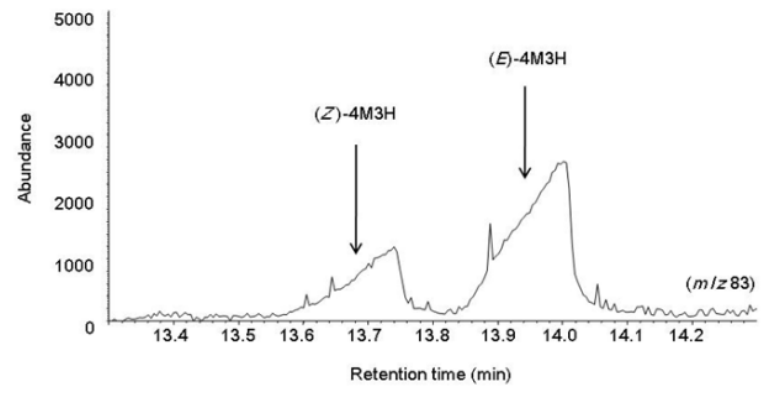

Fig. 3: The extracted ion chromatogram of 4-methyl-3hexenoic acid $(4 \mathrm{M} 3 \mathrm{H})$ formed in the maillard reaction of L-isoleucine with xylose, via Multidimensional Gas Chromatography-Mass Spectrometry (MDGC-MS) (selected ion, $\mathrm{m} / \mathrm{z}$ 83; column (second dimension), InertCap 1)

affords Strecker acids derived from amino acids (Hofmann et al., 2000) and thermal decomposition of sugars provides an aliphatic acid (Ginz et al., 2000). In this study, we examined the Maillard reactions of amino acids with sugars.

Firstly, we studied the Maillard reactions of amino acids (L-isoleucine, glycine, L- $\alpha$-alanine, L-valine and L-leucine) found in green coffee (Arnold et al., 1994) with xylose during heat treatment to screen essential amino acids. The mixtures dissolved in the phosphate buffer $\left(\mathrm{pH}\right.$ 6.0) were heated for $1 \mathrm{~h}$ at $120^{\circ} \mathrm{C}$ in an autoclave. The resulting volatiles were extracted and analyzed via GC-O. The analysis showed that the odor of $(E)-4 \mathrm{M} 3 \mathrm{H}$ was perceived only in the reaction using L-isoleucine (Table 2, No. 1). The MDGC-(EI) MS analysis provided chromatographic peaks of (Z)-and (E)-4M3H (Fig. 3). In addition, it was found that the Maillard reactions of L-isoleucine with other sugars such as fructose, glucose, rhamnose and sucrose, found in green coffee (Flament, 2001), afforded $(E)-4 \mathrm{M} 3 \mathrm{H}$ and its presence was confirmed by GC-O (Table 2, No. 6-9). These results indicate that $\mathrm{L}$-isoleucine and sugars are essential in the formation of $4 \mathrm{M} 3 \mathrm{H}$.

We carried out an additional experiment on the key compounds related to $(E)-4 \mathrm{M} 3 \mathrm{H}$ formation in the Maillard reactions. We studied the Maillard reactions of glycine with sugars (xylose, fructose, glucose, rhamnose and sucrose) in the presence of 2methylbutanal-the Strecker aldehyde generated via thermal degradation of L-isoleucine. We also studied the reactions of L-isoleucine with $\alpha$-dicarbonyl compounds (glyoxal, 2-oxopropanal, 2, 3-butanedione and 2, 3-pentanedione), or $\alpha$-hydroxy ketones (1hydroxy-2-propanone and 3-hydroxy-2-butanone). In addition, we examined the reactions of 2-methylbutanal with $\alpha$-dicarbonyl compounds or $\alpha$-hydroxy ketones in the presence of an equivalent amount of glycine as a catalyst. We observed $(E)-4 \mathrm{M} 3 \mathrm{H}$ in all reactions (Table 2, No. 10-26). From these results, we concluded that 2-methylbutanal (derived from L-isoleucine), $\alpha$ dicarbonyl compounds and $\alpha$-hydroxy ketones (derived from sugars) are the key compounds-the starting substances-in the nonstereoselective formation of $4 \mathrm{M} 3 \mathrm{H}$ via the Maillard reactions.

On the basis of these findings, we propose certain formation pathways starting from 2-methylbutanal in 
Route A

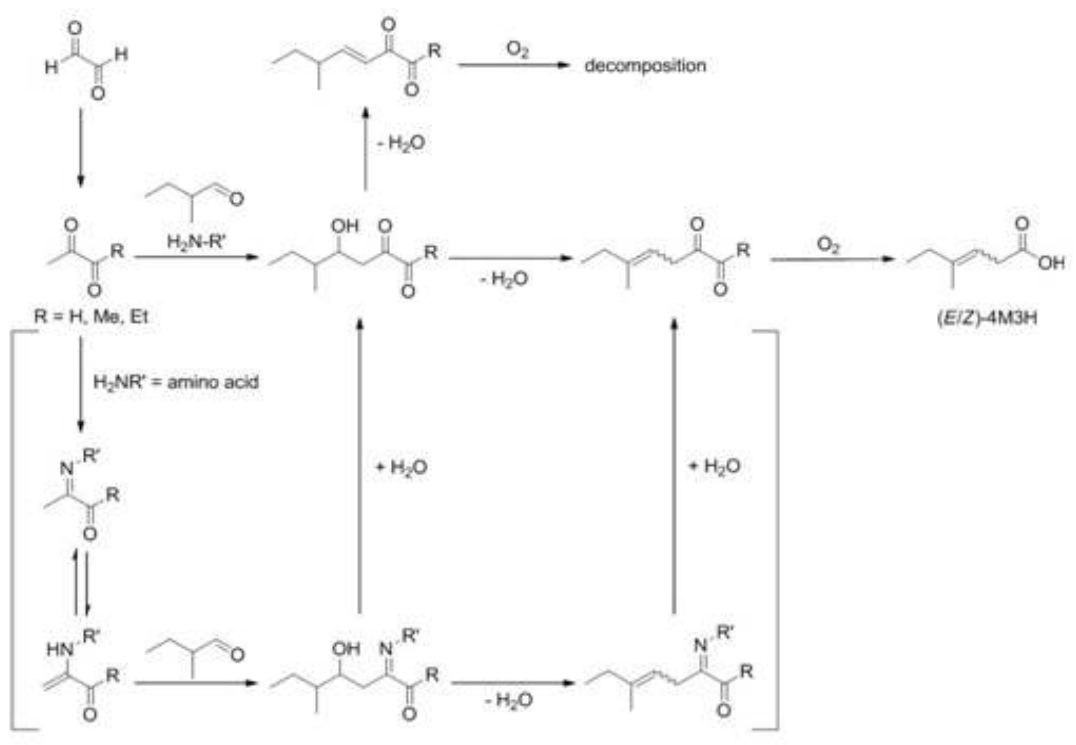

Route B

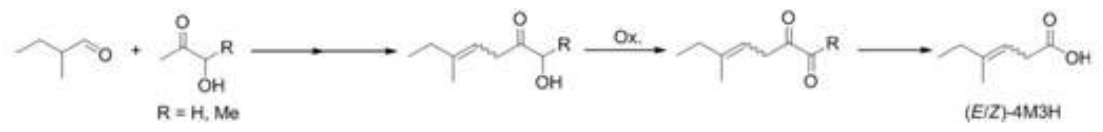

Route C

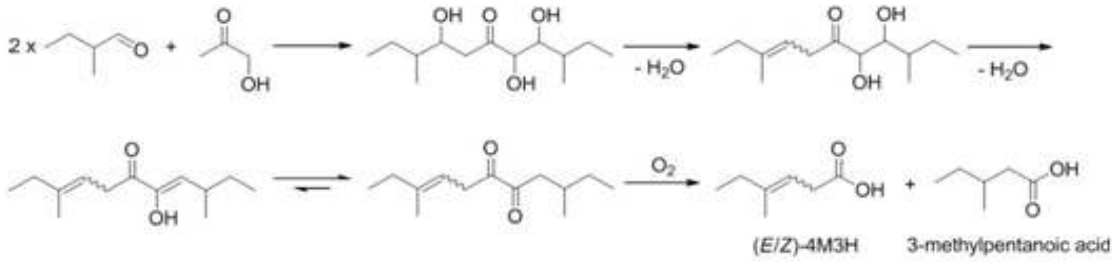

Fig. 4: The proposed formation pathways of 4-methyl-3-hexenoic acid (4M3H) in the model maillard reactions of L-isoleucine with sugars, starting from 2-methylbutanal and the sugar degradation compounds (glyoxal, 2-oxopropanal, 2, 3butanedione, 2, 3-pentanedione, 1-hydroxy-2-propanone and 3-hydroxy-2-butanone)

conjunction with $\alpha$-dicarbonyl compounds and $\alpha$ hydroxy ketones, as shown in Fig. 4. 4M3H may be nonstereoselectively formed via the following main pathways: route A with $\alpha$-dicarbonyl compounds (2oxopropanal, 2, 3-butanedione and 2, 3-pentanedione); and route $\mathrm{B}$ with $\alpha$-hydroxy ketones (1-hydroxy-2propanone and 3-hydroxy-2-butanone).

Route $\mathrm{A}$ is represented through the following reaction sequence: an amine-catalyzed aldol reaction of $\alpha$-dicarbonyl compounds with 2-methylbutanal, followed by $\beta, \gamma$-dehydration and lastly an oxidative $\alpha$ dicarbonyl cleavage (Davídek et al., 2006) to acids. The reaction pathway with glyoxal is unclear; it reacts with the amino acid to convert into 2-oxopropanal and 2, 3butanedione (Yaylayan and Keyhani, 1998). Therefore, glyoxal may be indirectly related to the formation via route $\mathrm{A}$.

Route B may be described through a similar sequence: an amine-catalyzed aldol reaction of $\alpha$ hydroxy ketones at the $\alpha$-position (unattached to hydroxyl group), followed by $\beta, \gamma$-dehydration and then the oxidation of $\alpha$-hydroxy ketones to $\alpha$-diketones (Novotný et al., 2007; Belitz et al., 2009) and subsequent oxidative cleavage of the resulting diketones to acids. As shown in Fig. 4, a different route $\mathrm{C}$ is also proposed in the case of 1-hydroxy-2propanone: a double aldol reaction might occur at two $\alpha$-positions to finally afford $4 \mathrm{M} 3 \mathrm{H}$, along with 3 methylpentanoic acid (which was also detected in roasted coffee and in the Maillard reactions (data not shown)). 
The aldol reactions and $\beta, \gamma$-dehydrations in the proposed formation pathways were assumed to be minor reactions. It is unlikely that amino acid-catalyzed aldol reactions of $\alpha$-dicarbonyl compounds occur, because following enaminations, the Strecker reactions of amino acids with $\alpha$-dicarbonyl compounds proceed predominantly to afford Strecker aldehydes and acids (Hofmann et al., 2000; Pripis-Nicolau et al., 2000). Even if the desired aldol reactions occur, it is improbable for the subsequent $\beta, \gamma$-dehydrations to proceed, so that the corresponding conjugated unsaturated compounds such as the final product 4methyl-2-hexenoic acid (4M2H) may be formed; 4M2H was not detected in roasted coffee (data not shown), probably because the reactive intermediate (conjugated unsaturated diketone) does not undergo the final oxidative $\alpha$-dicarbonyl cleavage. Instead, it may decompose via oxidative cleavage of the resulting $\alpha, \beta$ unsaturated aliphatic moiety. Since there were minor reactions in the formation pathways, it is a reasonable assumption that $4 \mathrm{M} 3 \mathrm{H}$ is a minor volatile acid seen in the model Maillard reactions, which is found in roasted coffee.

Based on these findings, we conclude that $(Z)$-and $(E)-4 \mathrm{M} 3 \mathrm{H}$, first identified in roasted coffee, may be formed nonstereoselectively in the Maillard reactions of L-isoleucine with sugars during the actual roasting process.

\section{CONCLUSION}

4-Methyl-3-hexenoic acid (4M3H) was identified for the first time in roasted coffee. $4 \mathrm{M} 3 \mathrm{H}$ was formed in the Maillard reactions of L-isoleucine with sugars. 2Methylbutanal derived from L-isoleucine was a key compound in this formation. $\alpha$-Dicarbonyl compounds and $\alpha$-hydroxy ketones were additional key compounds. The formation pathways for $4 \mathrm{M} 3 \mathrm{H}$ in the Maillard reactions were proposed.

\section{REFERENCES}

Akutsu, T., K. Sekiguchi, T. Ohmori and K. Sakurada, 2006. Individual comparisons of the levels of (E)3-methyl-2-hexenoic acid, an axillary odor-related compound, in Japanese. Chem. Senses, 31(6): 557-563.

Arnold, U., E. Ludwig, R. Kühn and U. Möschwitzer, 1994. Analysis of free amino acids in green coffee beans. I. Determination of amino acids after precolumn derivatization using 9fluorenylmethylchloroformate. Z. Lebensm. Unters. For., 199(1): 22-25.

Belitz, H.D., W. Grosch and P. Schieberle, 2009. Food Chemistry. 4th Edn., Springer-Verlag, Berlin, pp: 248-339.
Blank, I., A. Sen and W. Grosch, 1992. Potent odorants of the roasted powder and brew of Arabica coffee. Z. Lebensm. Unters. For., 195(3): 239-245.

Davídek, T., E. Gouézec, S. Devaud and I. Blank, 2007. Fragmentation of pentose via $\beta$-dicarbonyl cleavage. Proceeding of the 9th International Symposium on the Maillard Reaction. Munich, September 1st-5th.

Davídek, T., F. Robert, S. Devaud, F.A. Vera and I. Blank, 2006. Sugar fragmentation in the Maillard reaction cascade: Formation of short-chain carboxylic acids by a new oxidative $\alpha$-dicarbonyl cleavage pathway. J. Agric. Food Chem., 54(18): 6677-6684.

Flament, I., 2001. Coffee Flavor Chemistry. 1st Edn., John Wiley and Sons, Chichester.

Ginz, M., H.H. Balzer, A.G.W. Bradbury and H.G. Maier, 2000. Formation of aliphatic acids by carbohydrate degradation during roasting of coffee. Eur. Food Res. Technol., 211(6): 404-410.

Hofmann, T., P. Münch and P. Schieberle, 2000. Quantitative model studies on the formation of aroma-active aldehydes and acids by Strecker-type reactions. J. Agric. Food Chem., 48(2): 434-440.

Hollnagel, A. and L.W. Kroh, 1998. Formation of $\alpha-$ dicarbonyl fragments from mono-and disaccharides under caramelization and Maillrad reaction conditions. Z. Lebensm. Unters. For., 207(1): 50-54.

Holscher, W. and H. Steinhart, 1994. Formation Pathways for Primary Roasted Coffee Aroma Compounds. In: Parliament, T.H., M.J. Morello and R.J. McGorrin (Eds.), Thermally Generated Flavors. American Chemical Society, Washington, DC, pp: 206-217.

Holscher, W., O.G. Vitzthum and H. Steinhart, 1990. Identification and sensorial evaluation of aromaimpact-compounds in roasted Colombian coffee. Cafe Cacao The, 34(3): 205-212.

Kováts, E., 1958. Gas-chromatographische charakterisierung organischer verbindungen. Teil 1: Retentionsindices aliphatischer halogenide, alkohole, aldehyde und ketone. Helv. Chim. Acta, 41(7): 1915-1932.

Miyazato, H., S. Hashimoto and S. Hayashi, $2013 \mathrm{a}$. First identification of the odour-active unsaturated aliphatic acid (E)-4-methyl-3-hexenoic acid in yuzu (Citrus junos Sieb. ex Tanaka). Flavour Frag. J., 28(1): 62-69.

Miyazato, H., M. Nakamura, S. Hashimoto and S. Hayashi, 2013b. Identification of the odouractive cyclic diketone cis-2, 6-dimethyl-1, 4cyclohexanedione in roasted Arabica coffee brew. Food Chem., 138(4): 2346-2355.

Mizutani, S., T. Hayashi, H. Ueda and C. Tatsumi, 1971. Microbiological conversion of terpenes part IX. Conversion of linalool. Nippon Nogei Kagaku Kaishi, 45(8): 368-373. 
Mottram, D.S., 1994. Flavor Compounds Formed During the Maillrad Reaction. In: Parliament, T.H., M.J. Morello and R.J. McGorrin (Eds.), Thermally Generated Flavors. American Chemical Society, Washington, DC, pp: 104-126.

Narushima, H., T. Omori and Y. Minoda, 1982. Microbial Oxidation of $\beta$-Myrcene. In: Vezina, C. and K. Singh (Eds.), Advances in Biotechnology. Pergamon Press, Oxford, pp: 525-531.

Nishimura, O. and S. Mihara, 1990. Investigation of 2hydroxy-2-cyclopenten-1-ones in roasted coffee. J. Agric. Food Chem., 38(4): 1038-1041.

Novotný, O., K. Cejpek and J. Velíšek, 2007. Formation of $\alpha$-hydroxycarbonyl and $\alpha$-dicarbonyl compounds during degradation of monosaccharides. Czech J. Food Sci., 25(3): 119-130.

Pripis-Nicolau, L., G. de Revel, A. Bertrand and A. Maujean, 2000. Formation of flavor components by the reaction of amino acid and carbonyl compounds in mild conditions. J. Agric. Food Chem., 48(9): 3761-3766.

Shibamoto, T., 1989. Volatile Flavor Chemicals Formed by the Maillard Reaction. In: Parliament, T.H., R.J. McGorrin and C.T. Ho (Eds.), Thermal Generation of Aromas. American Chemical Society, Washington, DC, pp: 134-142.

Takeuchi, K., Y. Hasegawa, H. Ishida and M. Kashiwagi, 2012. Identification of novel malodour compounds in laundry. Flavour Frag. J., 27(1): 89-94.
Tomiyama, K., H. Aoki, T. Oikawa, K. Sakurai, Y. Kasahara and Y. Kawakami, 2012. Characteristic volatile components of Japanese sour citrus fruits: yuzu, sudachi and kabosu. Flavour Frag. J., 27(5): 341-355.

Ullrich, F. and W. Grosch, 1987. Identification of the most intense volatile flavour compounds formed during autoxidation of linoleic acid. Z. Lebensm. Unters. For., 184(4): 277-282.

Weckerle, B., T. Gáti, G. Tóth and P. Schreier, 2002. 3Methylbutanoyl and 3-methylbut-2-enoyl disaccharides from green coffee beans (Coffea arabica). Phytochem., 60(4): 409-414.

Weenen, H. and J.G.M. van der Ven, 2001. The Formation of Strecker Aldehydes. In: Takeoka, G.R., M. Güntert and K.H. Engel (Eds.), Aroma Active Compounds in Foods. American Chemical Society, Washington, DC, pp: 183-195.

Wöhrmann, R., B. Hojabr-Kalali and H.G. Maier, 1997. Volatile minor acids in coffee I. Contents of green and roasted coffee. Dtsch. Lebensm. Rundsch, 93(6): 191-194.

Yaylayan, V.A. and A. Keyhani, 1998. The Origin and Fate of $\alpha$-Dicarbonyls Formed in Maillard Model Systems: Mechanistic Studies using 13C- and 15N-Labelled Amino Acids. In: O'Brien, J., H.E. Nursten, M.J.C. Crabbe and J.M. Ames (Eds.), the Maillard Reaction in Foods and Medicine. The Royal Society of Chemistry, Cambridge, pp: 51-56. 